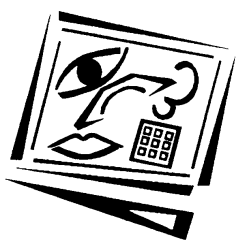

\title{
Talking about science in interactive whiteboard classrooms
}

Karen Murcia and Rachel Sheffield

Edith Cowan University

\begin{abstract}
Teachers using interactive whiteboards (IWB) effectively can engage and motivate students with a range of digital resources to explore science's role in making sense of our world and to construct knowledge of key scientific concepts. The case study research described in this paper illustrates how interactive pedagogies in the IWB classroom were used to support whole class substantive discourse about science. A sociocultural framework structured the exploration of the discourse surrounding four teachers and their students' use of IWB technology in their primary science classrooms. Action research methods and a professional learning intervention were used for both exploring and developing teachers' understanding of the interactive technology and its impact on the nature of classroom talk. Comparing video captured lessons with and without the use of the IWB provided some initial evidence of an increase in students' participation in substantive science conversations and exploratory talk. The preliminary analysis of the data summary across the four case studies suggested that the teachers were using more open questions, greater wait time and required greater participation from students. This research suggests that teachers' effective IWB pedagogy impacts positively on the way students talk about science. Seven principles of effective interactive pedagogy focused on enhancing discourse emerged from the action research. It is recommended that these principles be used with IWB technology to scaffold deep substantial science discourse, which is essential in developing students' scientific literacy.
\end{abstract}

\section{Introduction}

Classroom technology is evolving quickly and so must teachers' pedagogy in order to meet the learning needs of contemporary 'digital students'. The Australian Government's Digital Education Revolution recognises the changing needs and motivation of these students and aims to contribute sustainable and meaningful enhancements to teaching and learning and prepare students for further education and for living and working in a digital world. This initiative recognises that Australian students need greater access to, and more sophisticated use of, ICT as well as welltrained teachers to integrate technology into teaching and learning (DEEWR, 2008). Improving teachers' expertise and students' scientific literacy learning outcomes are also strategic priorities for the Australian Government and it is argued that ICT integration is a key reform strategy.

Research on effective classroom practice provides evidence to support a focus on integrating ICT across the curriculum. For example, Hackling and Prain (2005) found from their analysis of a series of seminal Australian research and professional documents that the dominant characteristics of effective science teaching were life and 
community relevant science learning experiences, active engagement and inquirybased learning focused on outcomes that contribute to scientific literacy. They also stated that in effective science teaching "Information and Communication Technologies (ICT) are exploited to enhance learning" (p. 19). The need to integrate the use of ICTs into science learning and teaching was also explicitly addressed in the Australian School Science Education National Action Plan. It was recommended as a priority action that teaching and learning approaches be encouraged that promote the outcome of scientific literacy and specifically stated, "students learn science by seeking understanding from multiple sources of information, ranging from hands-on investigation to Internet searching" (Goodrum \& Rennie, 2007, p. 14).

Interactive whiteboards (IWB) are reported to be an effective way for teachers to interact with and converge digital content and multimedia learning resources in the classroom (Betcher \& Lee, 2009; Hennessy, Deaney, Ruthven \& Winterbottom, 2007; Murcia, 2008a). Particularly as research suggests it is the interactivity in online digital learning activities that students most value $(\mathrm{Ng}, 2008)$. The IWB enables students and teachers to interact with all the functions of a desktop computer through the board's large touch sensitive surface.The IWB essentially acts as a port through which any computer run ICT function can be displayed and interacted with. Teachers who use effective interactive pedagogies with the IWB can enhance the learning benefits of interactive websites and ICT generally by bringing the experience to the whole class or alternatively, supporting small group learning with ICT. Teachers can engage students with computer-based learning without being hidden behind a desktop screen or isolating learners at a computer (Betcher \& Lee, 2009; Murcia, 2008b).

Educational research suggests effective interactive pedagogy with an IWB can engage and motivate students to explore science's role in making sense of our world and to understand key scientific concepts. For example, research conducted by Hennessy et al. (2007) and Murcia (2008a) investigated how interactive whiteboard technology could be used to support science teaching and learning. The UK study conducted by Hennessy et al. (2007) reported pedagogical strategies for using the IWB in school science. They found teachers exploited the dynamic and manipulative nature of the technology in order to "focus thinking on key scientific concepts and processes, to unpack, explain and organically build them up and to negotiate new, shared understandings" (p. 297). The Australian study conducted by Murcia (2008a) found that active science learning connected to social contexts was increasingly possible with the use of interactive whiteboard technology. The technology enabled the development of creative science teaching resources that linked directly to Internet sites and online activities. It enabled fluid access to online real life science contexts which could be annotated at the board with the interactive tools. In both research contexts, multimedia resources were converged efficiently into a sequence of learning activities with time efficient links embedded into the IWB software's notebook.

Teachers' facilitation of discourse when using the IWB emerged as a dominant theme from the research. Murcia (2008a) found that the IWB created a fluid space where interactive communication allowed the teacher and students to "explore science ideas together, pose questions and reconcile scientific and informal ideas" (p. 20). Integrated with reported interactive activities were higher order questions and student led discussions: "Questioning was the means for focusing students' attention, provoking action and for making connections" (Murcia, 2008a, p. 20). Higgins, Beachamp and Miller (2007) in their review of the literature on interactive whiteboards further 
identified research evidence that "interactivity is most effectively sustained through effective questioning as well as a wider range of activity" (p. 216). Strategies for managing effective questioning and discussion are a key dimension of productive interactive pedagogy. However, Hennessey et al. (2007) caution that the "ever present concern to maintain lesson pace means that ironically IWB use may afford even less thinking time and opportunity for pupil input than other forms of educational technology" (p. 285). This concern, coupled with an understanding of the crucial role played by language in sustaining effective interactive pedagogy in inquiry-based science, provided the impetus for further research into the impact of IWB technology on the nature and quality of discourse in the science classroom.

In response, this case study research was conducted with four teachers from two Western Australian primary schools. The aim of this research was to explore the impact of IWB technology on discourse in the primary science classroom. The case study teachers introduced interactive whiteboards into their teaching of primary science as a part of a professional learning intervention. They used the technology to enhance and extend their implementation of selected primary science units from the Australian Academy of Science resource, Primary Connections. This paper reports the methods and preliminary findings of this research. Firstly, influential literature in the field of discourse analysis and science inquiry is reviewed to establish the research framework. A focus is then given to the action research methods used to explore the teachers' use of IWB technology and the nature of whole class discourse in their science classrooms. The data analysis process is explained and evidence is then presented to show the impact of teachers' IWB pedagogy on the way their students talked about science. The principles of effective interactive pedagogy supporting substantive science conversations emerging from the case study are presented as an outcome of the research.

\section{Frameworks for exploring science discourse}

To begin, it is essential from a sociocultural perspective of science education to give consideration to the type of questions and the nature of discourse that supports student learning and their development of scientific literacy. Through this lens science education is viewed as a process of enculturing students into particular ways of knowing and representing the world and making claims from a scientific perspective (Hackling, Peers \& Prain, 2007). It is evident that science has a distinctive social language that Mortimer and Scott (2003) argue "can be thought as a tool, offering a distinctive way of talking and thinking about the world" (p. 13). An important aspect of enculturing is the use of language supported, inquiry-based activities that enable students to meaningfully construct an understanding of science. It is argued that engaging students with public discourse in which they experience meaningful exploratory talk and substantive conversations, contributes to their development of scientific literacy.

Mortimer and Scott (2003) identified two dimensions of classroom talk and described these as interactive/non-interactive and dialogic/authoritative. They classified classroom talk as interactive when multiple students and the teacher contribute to a whole class conversation and non-interactive when one voice dominated or excluded others' contribution. They considered talk to be dialogic when many ideas are presented and authoritative when consideration is given to only one point of view, which in science is often the dominantly accepted scientific conception or explanation. 
In addition, talk was considered to be interactive when multiple students and the teacher contribute to a whole class conversation and alternatively non-interactive when one voice dominated or excluded others' contribution. Combining Mortimer and Scott's (2003) dimensions resulted in the identification of four communicative approaches, as shown in Figure 1.

\begin{tabular}{|c|c|c|}
\hline & Interactive & Non-interactive \\
One voice
\end{tabular}

Figure 1: Dimensions of discourse and the communicative approaches (based on Mortimer \& Scott, 2003)

Mortimer and Scott's (2003) interactive-dialogic communicative approach is consistent with the notion of dialogic teaching developed by Robin Alexander (2008) which he describes as collective, reciprocal, supportive, sustained, cumulative and purposeful.

Inquiry-based teaching and learning is based on the social constructivist view that students must actively construct understandings through making sense of experiences using their prior knowledge and through conversation with others (Driver, Asko, Leach, Mortimer \& Scott, 1994). This suggests it is important to match the nature of discourse to the inquiry process in primary science classrooms. When discourse is explored in relation to the phases of inquiry and specifically the 5Es constructivist model (Bybee, 1997; Australian Academy of Science, 2005) it is evident that different communicative approaches are required to achieve the learning and teaching purposes of each phase. These phases are described by Hackling, Smith \& Murcia (2010) in the following quote.
Teaching must start by exploring students' prior beliefs (Engage) and then provide experiences of science phenomena so as to work on students' ideas (Explore), before formal scientific explanations are introduced and developed on the social plane (Explain). Subsequently, students should be given an opportunity to appropriate the new scientific ideas and to apply them in a student-planned investigation (Elaborate) (p. 18).

Logically, these ideas suggest teachers' use of the IWB and development of digital interactive resources should be matched to the phase of inquiry and facilitate appropriate substantive classroom talk about science. Classroom talk that is substantive emphasises the construction of students' knowledge of and about science. The direction and momentum of the conversation is maintained by teachers' questioning, use of wait time, acceptance of a range of student ideas and asking further questions that seek clarification, elaboration or evidence for assertions from the students (Koufetta-Menicou \& Scaife, 2000). The talk happening on the social plane of the classroom becomes cumulative and supports collaborative construction of knowledge and understanding (Hackling et al., 2010).

During the engage and explore phases of inquiry when the instructional purpose is to elicit students' prior conceptions and work on students' ideas, the discourse is ideally 
interactive/dialogic - that is many voices and ideas. Achieving this depends on the use of open questions that allow a range of ideas to be presented. Longer wait times and non-evaluative teacher responses encourage more students to participate in the conversation. While exploring a concept, students should be constructing a scientific understanding. At the explain phase it is then expected that the communicative approach becomes increasingly interactive/authoritative; still many voices but each talking about the accepted scientific view or idea. Making this transition requires teachers to use more closed questions to focus and direct the conversation towards the desired outcome or scientific conception. Teacher feedback to student responses should be evaluative in order to clarify understanding and avoid any confusion as to which is the accepted scientific idea (Hackling et al., 2010).

\section{The IWB and discourse research project}

The current research project reported in this paper used the Mortimer and Scott (2003) and Hackling et al. (2010) frameworks in conjunction with action research principles to explore the impact of interactive whiteboard (IWB) technology on the nature of discourse in primary science.

\section{The participating teachers}

The project ran for one year within a school cluster that included three primary schools and a high school. Each school nominated two teachers who were already using an IWB or interested in having one provided and fixed in their classroom. There were six primary school teachers and two high school teachers participating in the project. From this group, four primary school teachers (from two schools) were selected for the case study research, as the focus of the study was the primary level and these four teachers completed all aspects of the project. Pseudonyms were assigned to each teacher for the purpose of the research and reporting.

School One: Janet and Lucy

Janet was teaching a Year 5/6 split class (ages 10 to 11). The Primary Connections science topics programmed for the year included Spinning in Space and Earthquake Explorers. Janet had been using interactive whiteboard technology in her classroom for two years prior to the project. She had used the technology for accessing the Internet and engaging students with online activities and videos.

Lucy was teaching a Year 6/7 split class (ages 11 to 12). Like Janet, her science program was focused on Earth and Beyond outcomes from the Western Australian Curriculum. Lucy and Janet worked collaboratively during the project and shared ideas and resources. Lucy used the Earthquake Explorers unit first and followed with Spinning in Space. Lucy had experienced IWB technology and as such was keen to have one installed in her classroom. She stated, "It is the way teaching is going. Technology is a big part of the students' lives and we as teachers need to begin incorporating more technology into our lessons".

School Two: Elli and Tania

Elli was teaching a Year 6 class (aged 11). The Primary Connections science topics programmed for the year included Package it Better, It's Electrifying and Marvellous Micro-organisms. Elli had been using interactive whiteboard technology in her classroom for five years prior to the project. She reported that on average she 
integrated the IWB into $80 \%$ of her teaching. Elli explained that she used the IWB to access web-based interactive activities and for promoting student engagement.

Tania was teaching a Year 5 class (aged 10). She initially started the year working in the Life and Living strand on Mini-beasts. Her science program then included Primary Connections units Its Electrifying and Smooth Moves. At the start of the project Tania had just received an IWB, which was permanently fixed to the wall in her classroom and she had not yet started to use it in her teaching.

\section{Action research and teachers' professional learning}

Action research principles contributed to the structure of the IWB and Discourse Project. Weinstein (1995) describes action research as a way of learning from our actions and from what happens around us by taking the time to question and reflect on this in order to gain insights and consider how to act in the future. The project structure aimed to facilitate practical action, based on the learning needs and interests of the participating teachers, while supporting the teachers' professional learning about IWB technology and discourse in science. This was particularly important given the range in IWB technology experience amongst the participating teachers. The action research approach contributed to building a research partnership with the teachers in which their prior and diverse professional experiences, knowledge and classroom expertise were recognised, drawn from and built on to. This process contributed to the development amongst the participating teachers of a sense of critical reflection or questioning of existing perspectives of teaching and student learning. Throughout the project teachers were encouraged to act as critical friends to their school-based partner and then more broadly to the whole project team. There was a dual focus, firstly on action in the form of change and then research in the form of understanding (Murcia, 2005). The project was intended to be a flexible and participatory process, alternating between planning, acting, describing and critically reflecting. The teachers were able to contribute to the research by sharing and reflecting on their practice in the science classroom. This occurred when researchers visited the teachers at their school and at a series of IWB Hub meetings held at intervals throughout the school year.

The IWB Hub meetings were critical to maintaining the momentum of the project, as well as teachers' attention to discourse strategies and their development of IWB skills. Teachers received expert input at points of need both from the researchers and an interactive technologies education consultant from industry. Teachers also received three full days of professional learning in relation to inquiry-based science, discourse in science and IWB skills development in which interactive pedagogies supporting substantive science discourse were emphasised. A session for debriefing project activity was included in each meeting and was guided by the following question set:

- What has my class been doing in science since our last meeting?

- What have I been doing on the IWB in my science lessons?

- What have I noticed about my students' learning when I used the IWB in the science classroom?

In addition, an online research site was developed to further support the teachers' professional learning and to provide access to digital resources. This research site was password protected and only available to members of the research team as it contained video of classroom action and invited feedback through a discussion forum. 
At a mid-point in the project the teachers had the opportunity to demonstrate to the research team the IWB science notebook they had developed to support a Primary Connections unit. These demonstrations resulted in IWB skill sharing amongst the teachers and generated professional reflection. The teachers provided constructive feedback on each interactive notebook design and its implementation in the classroom. Group discussion was focused on the teachers' scaffolding of communicative approaches matched appropriately to each stage of inquiry. The teachers were later given time to redesign and further expand their approach to IWB notebook development in the context of a second Primary Connections unit. The final IWB Hub meeting was used to celebrate teachers' work and completion of the project. Industry partners, representatives of each participating school's executive group and members of the science education community were invited to attend the 'Showcase of Teachers Creativity'. Each teacher presented interactive examples from their Primary Connections science notebooks and shared their personal learning journey experienced as a member of the project team.

\section{Video capture and analysis}

The technology based and interactive nature of the IWB learning environment required video recording of classroom action in order to capture and explain the dynamic modes of learning and teaching, and the surrounding discourse in primary science lessons. The participating teachers were filmed at the start of the project, delivering a Primary Connections lesson without using the IWB. This pre-IWB intervention lesson provided the baseline data for discourse analysis. At the conclusion of the project after teachers had participated in IWB Hub Meetings and the research training days as part of the action research process, they were again videoed but this time using the IWB as they delivered a science lesson. The post IWB intervention lesson was matched to the phase of inquiry addressed in the pre IWB lesson recording. This allowed for a direct pre- and post-IWB intervention comparison of discourse to be made in a particular phase of science inquiry.

Careful consideration and management of the video capturing of science lessons was maintained throughout the project. Video recordings of science lessons were made using a single camera with a wide angle lens placed at the back of the classroom out of the students' line of sight. This camera was fixed on a tripod to minimise its influence on classroom activity. The teachers wore a lapel microphone linked to a receiver on the camera so that a clear audio recording was obtained. A second desktop microphone also linked to a receiver on the camera was used to capture student talk during whole class discourse.

Field notes from lesson observations were used to write brief lesson outlines and to identify the phase of inquiry and intended instructional purpose of the lessons. Segments of video recordings that showed parts of lessons involving whole-class discussion about science were viewed and the talk transcribed using NVivo software (QSR International, 2008). Each segment was then referred to as an episode of whole class substantive science discussion. Some episodes included talk about classroom procedures and included the teacher giving instructions about tasks. These were not transcribed and did not contribute to the data for analysis. In each of the episodes of whole class substantive science discussion, the incidence of communicative approaches and discourse moves used by the teacher (e.g., types of questions and wait time), and the nature of students' participation in classroom talk were coded into 'nodes' or categories using the NVivo software. The validity of the coding scheme was first checked by a group of five researchers working within the same conceptual framework 
for discourse analysis. Definitions were clarified and illustrative examples of each coding node were obtained. Coding into discourse nodes was then completed for both the pre- and post-IWB intervention lessons from each participating teacher.

The purpose of this paper is to show some preliminary results from the analysis summary across the four case studies rather than an in-depth analysis of the discourse in each teacher's classroom. This preliminary analysis is firstly contextualised with the interactive pedagogies observed in the teachers' classrooms and discussed in both the professional learning hub meetings and post lesson semi-structured interviews. Interviews with the teachers and their reflections during the professional learning sessions are used to show how the IWB technology facilitated changes to their pedagogy and facilitation of whole class science discourse.

\section{Interactive pedagogies and discourse in the primary science classroom}

As with any other classroom resource or technological tool, it is what the teacher does with an IWB that is far more important than the technology itself. Higgins et al. (2007) shares this view; "good teaching remains good teaching with or without the technology; the technology might enhance the pedagogy only if the teachers and pupils engaged with it and understood its potential in such a way that the technology is not seen as an end in itself but as another pedagogical means to achieve teaching and learning goals" (p. 217). Technology-led initiatives in education are often not accompanied by an adequate understanding of the technology's impact on pedagogy. Evidence from the initial uptake of IWB technology could support this inference (Warwick \& Kershner, 2008). The tool has been observed complementing traditional teacher-led, whole class learning where the IWB is simply used as a surface for writing notes or projecting images. Yet teachers using effective interactive pedagogies do much more as they become "critical agents in mediating the technology to provide a more dynamic, interactive and appropriate learning experience" (Rudd, 2007, p. 6).

In this project, features of the IWB software were used by the teachers to enhance interactivity between themselves, the learning resources and the students. They used software tools and simple design techniques to promote active learning with manipulations such as drag and drop; hide and reveal; layering, colour, shading and highlighting; annotating with digital ink, matching equivalent terms and movement for sorting and classifying. The teachers used the IWB to facilitate an ICT rich learning environment and to generate a social learning space that brought the whole class together. The following seven principles of effective interactive pedagogy that facilitated substantive whole class science discourse emerged from the teachers' use of the IWB.

\section{Engaging and appealing interactive displays}

Pictures, diagrams and photos were imported or captured by the teachers to produce visually appealing notebooks. These were displayed on the IWB and were often interactive as the teachers and students would edit, move objects or annotate information at the board. Elli explained how she used colour and interesting images in the creation of her science IWB notebook to engage students. She stated, "Colour and images are motivating and a good guide or start to discussion. Using animations, films and diagrams that students can interact with get the children involved and active." 


\section{Accessing online information}

A range of online learning resources were accessed via links embedded by the teachers into their interactive notebooks. Teachers selected websites that provided current information about science concepts or provided relevant contexts or examples. They were observed highlighting key words in the online text and underlining so as to focus students' thinking and talk. For example, Lucy explained, "I would bring up text on the board, highlight points with the (digital ink) pen and discuss with the students."

\section{Linking in media files}

Virtual demonstrations, documentaries and real life action, such as an earthquake hitting a school were integrated into the classroom learning with media files held efficiently as a notebook attachment. The teachers achieved smooth transitions between questions and text to playing the attached media files. Janet explained, "I use videos as a prompt for discussion. Through using a variety of mediums to present the knowledge you can tap into children's different learning styles. It enriches the discussion and scientific language used".

\section{Interacting with online activities}

A range of online learning resources were used to support the students' learning while working on the IWB. Interactive sites and games were found to be the most effective in engaging students. Janet explained, "I use video, the gallery and online games to have whole class discussion. With the games it's great to have the students call out ideas and use their books to tell the student at the board the answer. It's loads of fun."

\section{Constructing a series of interactive activities to develop the scientific story}

Teachers were designing their notebooks in a way that built connections between the interactive activities, tasks at the students' desks and classroom conversations. The IWB notebook not only contained interactive activities but also well-structured, purposeful questions and clear diagrams and instructions for exploration at the desk. The notebook shaped and represented the learning journey which supported students' development of the scientific story. Lucy explained, "It helps my teaching because I can do a whole program or a plan on a notebook and each slide just follows on. I've got my questions there. My lessons are organised, a lot more organised. It's set out, the expectations for the students are there and they can see them in black and white on the board. Resources that were unavailable to us before are now; we can use them by accessing the Internet. Instead of me trying to photocopy pictures or find pictures in books."

\section{Reviewing learning}

The connected nature of the interactive notebooks allowed the teacher and or students to move quickly from one page of the learning experience to another. This allowed the content of the lesson to be easily reviewed or connections to be made to previous activities. Elli explained how she used the IWB to support her questioning and students' review of their investigations. She said, "There were other things happening on the board, like predicting what we think might happen. What circuit worked and what didn't work. Then having the children draw circuits on the board and looking at 
different parts of circuits and asking what's different about each, why this one worked and that one didn't work. I was getting the children to pose questions as well." Tania also valued the use of the IWB for reviewing student learning and consolidating concepts explored in the hands on investigations. She explained, "They (students) were excited when they knew they were going to have science because they were waiting to see what sort of things were going to happen on the IWB for that lesson. We still did hands on investigations but they liked to come back to see what was on the IWB and how it related to what they were doing. Also, it helped them to see their answers come up on the screen."

In addition, Lucy was beginning to explore the record function in the interactive whiteboard software and using it as a tool for capturing the students' talk surrounding their actions on the IWB interactive task. Recordings were being saved as a media file and later reviewed by the students and Lucy. This interactive pedagogy was extending the options available to students for showing and sharing what they knew about science. Lucy explained, "the students had been talking about how day and night occurs, and so as part of their presentation back to the class I asked a few students to come up and they actually drew on one of the slides what they thought day and night was and how it happened. But we also used the record button to record exactly what they were drawing and exactly what they were talking about."

\section{Using IWB tools to increase wait time}

The project teachers explored a range of IWB tools and interactive pedagogies to promote and support their facilitation of classroom discourse. For example, Lucy said, "I now tend to list a lot of my questions on the IWB, hide them with different techniques that the interactive whiteboard allows and then they're there if or when I need them. If I don't need some questions then I can skip over them". The teachers were observed using a range of IWB tools for enhancing questioning techniques and strategies. These included the use of the screen and spotlight functions, which they used to increase the wait time after a question and provide space for students to think. Lucy further explained, "you might have the answers hiding under the screen but you just want the kids to think about it before you bring it up. Students need a lot of prompting from time to time. So using the screen again or the hide and reveal or click and reveal activities, just helps them. It gives them extra time and you see the students think, oh yeah, I've got another idea." Teachers also used the screen or spotlight over an interactive whiteboard display to assist in focusing students thinking and talking to the key ideas in a science lesson. Interactive activities incorporating simple hide and reveal strategies were also used.

\section{Exploring the impact of an IWB action research intervention on science discourse}

The action research methods used in this research provided an insight into how teachers used interactive pedagogies with the IWB to facilitate whole class science discourse. The holistic view of the classroom gained from repeated observations, video capturing and interviews showed how teachers' used the technology to mediate the discourse process. The impact of these practices was then explored across the four case studies through the coding of discourse types and teacher strategies. This broad approach to the initial discourse analysis highlighted emerging trends in the data. 
To begin, the frequencies of communicative approaches, student participation types, quality of student talk, and teachers' questioning and wait time were determined through NVivo queries and compared pre- to post-IWB intervention. This provided evidence of the impact of the IWB intervention on discourse in the science classroom across the four case study teachers. Any changes in the discourse in these science classrooms would have been contributed to by both the use of the IWB technology during the lesson and also the professional learning the teachers experienced as a member of the research project. The descriptive analysis displayed in Tables 1 to 5 is based on the video data and coding for the four case study teachers' matched pre- and post-IWB intervention lessons. When videoed Lucy and Elli were working at the engage phase, Janet at the explain phase and Tania at the explore phase.

\section{Communicative approach}

The episodes of whole class science discussion within the videoed lessons aggregated across all four classrooms increased in number from 26 to 34 in total and these became increasingly interactive post-IWB intervention, as shown in Table 1. Teachers were requiring more students to participate in the discussion when using the IWB as shown by the increased percentage of episodes that were interactive, either combined with authoritative or dialogic talk post-IWB intervention ( $81 \%$ to $94 \%$ ). Talk was more often than not dominated by a single idea, which was appropriate in the explain phase lesson, but in the engage and explore phase discourse would ideally be more dialogic. While looking more closely at each episode within the summary it was evident that teachers were shifting from one communicative approach to another as the lesson progressed. For example Lucy's post intervention 'engage' lesson started interactivedialogic but became increasingly interactive-authoritative as the class focused on the scientific explanation of night and day.

Table 1: Percentage of episodes of various communicative approaches pre and post IWB intervention

\begin{tabular}{|c|c|c|c|c|}
\hline \multirow{2}{*}{$\begin{array}{l}\text { Communicative } \\
\text { approach }\end{array}$} & \multicolumn{2}{|c|}{$\begin{array}{c}\text { Pre-IWB } \\
\text { (without IWB) }\end{array}$} & \multicolumn{2}{|c|}{$\begin{array}{c}\text { Post-IWB } \\
\text { (with IWB) }\end{array}$} \\
\hline & No. & $\%$ & No. & $\%$ \\
\hline Interactive-authoritative & 9 & 35 & 16 & 47 \\
\hline Non-interactive-authoritative & 5 & 19 & 2 & 6 \\
\hline Interactive-dialogic & 12 & 46 & 16 & 47 \\
\hline Non-interactive-dialogic & 0 & 0 & 0 & 0 \\
\hline
\end{tabular}

\section{Student participation}

As shown in Table 2, the teacher required greater student participation in classroom discussion when teaching with the IWB. The frequency of episodes in which more than five students contributed to the discussion rose from 9 to 21 post-IWB intervention. Not only were more students contributing, but the number of instances when students elaborated statements comprising more than 50 characters of transcript also increased from 3 to 18 . Yet the majority of these student contributions were in response to a teacher's question or request for a response. There were only four examples across all of the eight videoed lessons when students contributed an idea without prompting from the teacher and only one example of a student-initiated question. 
Table 2: Frequency of student participation pre and post IWB intervention

\begin{tabular}{|l|c|c|}
\hline \multicolumn{1}{|c|}{ Student participation } & $\begin{array}{c}\text { Pre-IWB (without IWB) } \\
\text { frequency (n) }\end{array}$ & $\begin{array}{c}\text { Post-IWB (with IWB) } \\
\text { frequency (n) }\end{array}$ \\
\hline More than five participating students & 9 & 21 \\
\hline Elaborated utterances & 3 & 18 \\
\hline Student initiated talk (idea) & 0 & 4 \\
\hline Student initiated question & 1 & 0 \\
\hline
\end{tabular}

\section{Quality of student talk}

The overall quality of the student talk was higher in the post IWB intervention lessons, as seen in Table 3. The lessons taught by the teachers while using the IWB had a higher percentage $(13 \%)$ of student argumentation-reasoning type statements. There were 55 examples from the four IWB lessons in which students made or justified a claim. These included examples were students used evidence to support their claim or ideas. The occurrence of student exploratory talk also increased from $7 \%$ to $16 \%$ of the total talk contributed by students. This included students exploring ideas as they talked, clarifying and shaping thinking or trying out ideas while talking to others. Students' exploratory talk was directed towards the teacher as there was only one instance of a student directing their ideas to another student during a whole class conversation. The majority of the whole class substantive science discourse across the four classrooms continued to be predominantly of low quality with frequent one-word responses from the students.

Table 3: Frequency of quality student talk pre and post IWB intervention

\begin{tabular}{|l|c|c|c|c|}
\hline \multirow{2}{*}{\multicolumn{1}{c|}{ Quality of student talk }} & \multicolumn{2}{c|}{ Pre-IWB (without IWB) } & \multicolumn{2}{c|}{ Post-IWB (with IWB) } \\
\cline { 2 - 5 } & No. & $\%$ & No. & $\%$ \\
\hline Argumentation-reasoning & 8 & 3.0 & 55 & 13.0 \\
\hline Exploratory talk & 19 & 7.0 & 71 & 16.0 \\
\hline Student to student & 0 & 0.0 & 1 & 0.5 \\
\hline Other (low quality) & 244 & 90.0 & 304 & 70.5 \\
\hline
\end{tabular}

\section{Teachers' question types}

The number of questions asked by teachers doubled post-IWB intervention across the four lessons, as shown in Table 4. It was evident from the data that closed questions contributed a smaller proportion of the total number of questions posed by the teachers during lessons with the IWB. Alternatively, the teachers' use of open questions increased post-IWB intervention. When using the IWB there were a greater percentage of open questions posed by the teacher which aimed to elicit a range of student ideas. The percentage of open ideas questions rose from $46 \%$ to $59 \%$. The percentage of open questions that required students to describe or explain an idea also increased, that was from $3.5 \%$ to $10.5 \%$ when the IWB was in use. Teachers were observed following up a student answer or comment and asking them to explain their thinking or provide evidence for inferences that may have been made. It was evident from classroom observations and analysis of the video data that the type of question posed by the teacher directly affected the students' responses. The teachers used closed questions for two main purposes - mostly to check students were understanding ideas and instructions, but also to clarify and focus students' thinking on a single science concept. 
Table 4: Frequency of teachers' question type pre-IWB and post-IWB intervention

\begin{tabular}{|l|c|c|c|c|}
\hline \multirow{2}{*}{ Question types } & \multicolumn{2}{c|}{ Pre-IWB (without IWB) } & \multicolumn{2}{c|}{ Post-IWB (with IWB) } \\
\cline { 2 - 5 } & No. & $\%$ & No. & $\%$ \\
\hline Closed & 50 & 41.0 & 54 & 21.0 \\
\hline Open description & 9 & 7.5 & 21 & 8.5 \\
\hline Open explanation & 4 & 3.5 & 27 & 10.5 \\
\hline Open ideas & 56 & 46.0 & 151 & 59.0 \\
\hline Open reason-justification & 3 & 2.0 & 2 & 1.0 \\
\hline
\end{tabular}

\section{Teachers' use of wait time}

The number of wait times greater than a count of 'one and two' increased when teachers were working with the IWB, as shown in Table 5. They were observed using tools in the IWB software to increase the wait time, which increase the space in the lesson for students to think. Teachers also used extended think time strategies such as 'think-pair-share'.

Table 5: Frequency of teachers' wait time strategies pre and post IWB intervention

\begin{tabular}{|l|c|c|}
\hline \multicolumn{1}{|c|}{ Wait time } & $\begin{array}{c}\text { Pre-IWB (without IWB) } \\
\text { frequency (n) }\end{array}$ & $\begin{array}{c}\text { Post-IWB (with IWB) } \\
\text { frequency (n) }\end{array}$ \\
\hline Extended think time strategy & 5 & 9 \\
\hline Extended wait time & 4 & 30 \\
\hline
\end{tabular}

This preliminary analysis and data summary illustrated emerging trends in the nature of discourse in the IWB primary science classrooms. It is intended that these trends will be used in the next stage of the research to further examine the data at a case level. Exploration of the data at a case level would represent the individual teachers' development of IWB supported discourse moves and how these impacted on the nature of talk in their science classroom.

\section{Conclusion}

In summary, the project teachers used the IWB technology as a tool for embedding ICTs into whole class science learning. Teachers and students participated in public discourse as they engaged with the wide range of multimedia activities and representations brought to the science classroom through the IWB technology. Selecting appropriate interactive resources and materials supported the teaching and learning purpose of each stage of the 5Es inquiry model and encouraged students to engage in whole class substantive science discussions. Teachers' use of different question types, responses and wait time matched appropriately to the phase of enquiry facilitated substantive conversations in the science classroom. The designing of an interactive notebook for the Primary Connections unit being taught assisted the teachers to structure the learning, focus students' attention and to facilitate substantive science discourse.

Comparing video captured lessons, matched in the stage of science inquiry and then, with and without the use of the IWB provided evidence of some increase in the amount and quality of student talk in whole class science conversations. Teachers were found using more open questions, greater wait time and requiring more reasoning and exploratory talk from students. This research provided evidence of teachers' effective IWB pedagogy impacting positively on the way students talked about science. The 
contribution of the professional learning the teachers received through the project's action research structure should not be underestimated. The increase in the quality of whole class science discourse during teaching and learning with the IWB should not only be attributed to the tools of the technology but also to the teachers' development of effective interactive pedagogy that focused on discourse.

The Australian national priority on ICT integration in education acknowledges that students need greater access to, and more sophisticated use of ICT, but also that welltrained teachers are essential to achieving this outcome. The findings of this case study research should not be over generalised, but in the context of the four teachers' primary science classrooms the use of interactive whiteboard technology enhanced student learning opportunities on the social plane of the classroom through whole class discourse practises. Consideration should now be given to teachers' professional learning that extends the principles of effective interactive pedagogies identified in this project more broadly. Exploiting the potential of IWB technology for scaffolding deep substantial discourse is essential in contemporary science learning and teaching that aims to achieve scientific literacy.

It has been recognised in this paper that interactive whiteboard technology is only as effective as the pedagogy that surrounds it. Teachers should be supported in their professional learning as they integrate new technology into their daily classroom practice. Research evidence must be considered and used to inform the development of interactive science resources and the associated approach to professional learning. Evidence based frameworks and strategies for effectively integrating interactive whiteboard technology will assist in increasing the depth and quality of discourse in the science classroom. A design model is recommended for developing interactive IWB notebooks for use in primary science classrooms. The model used in this research can be useful for developing original interactive dialogic science units that promote quality discourse matched appropriately to the phase of inquiry. Developments of this nature could enable teachers to not only use an IWB to support their existing pedagogies, but also to explore possibilities which ideally transform classroom practice and digital students learning opportunities.

\section{References}

Alexander, R. (2008). Culture, dialogue and learning: Notes on an emerging pedagogy. In N. Mercer \& S. Hodgkinson (Eds.), Exploring talk in school (pp. 91-114). London: Sage Publications.

Australian Academy of Science (2005). Primary connections: Plants in action. Canberra: Australian Academy of Science.

Betcher, C. \& Lee, M. (2009). The interactive whiteboard revolution. Victoria, Australia: ACER Press.

Bybee, R. (1997). Achieving scientific literacy: From purposes to practices. Portsmouth: Heinemann.

DEEWR (2008). Better practice guide: ICT in schools. [viewed 22 Sep 2008]

http: / / www.deewr.gov.au/Schooling/DigitalEducationRevolution/Pages/default.aspx

Driver, R., Asoko, H., Leach, J., Mortimer, E., \& Scott, P. (1994). Constructing scientific knowledge in the classroom. Educational Researcher, 23(7), 5-12.

Goodrum, D. \& Rennie, L. (2007). Australian school science education: National action plan 2008-2012, Volume 1, The national action plan. Canberra: Department of Education, Training and Youth Affairs. http: / / www.dest.gov.au/sectors/school_education/publications_ resources/profiles / Australian_School_Education_Plan_2008_2012.htm 
Hackling, M. \& Prain, V. (2005). Primary connections: Stage 2 trial - Research report. Canberra: Australian Academy of Science. [viewed 22 Sep 2008, verified 6 Jun 2010] http: / / www.science.org.au/reports/pcreport1.html

Hackling, M., Peers, S. \& Prain, V. (2007). Primary connections: Reforming science teaching in Australian primary schools. Teaching Science, 53(3), 12-16.

Hackling, M., Smith, P. \& Murcia, K. (2010). Talking science: Developing a discourse of inquiry. Teaching Science, 56(1), 17-22.

Hennessy, S., Deaney, R., Ruthven, K. \& Winterbottom, M. (2007). Pedagogical strategies for using the interactive whiteboard to foster learner participation in school science. Learning, Media and Technology, 32(3), 283-301.

Higgins, S. Beachamp, G. \& Miller, D. (2007). Reviewing the literature on interactive whiteboards. Learning, Media and Technology, 32(3), 213-225.

Koufetta-Menicou, C. \& Scaife, J. (2000). Teachers' questions - types and significance in science education. School Science Review, 81(296), 79-84.

Mortimer, E. F. \& Scott, P. H. (2003). Meaning making in secondary science classrooms. Maidenhead: Open University Press.

Murcia, K. (2005). Using action research principles for professional development: The Waikiki school experience. Action Learning and Action Research Journal, 10(1), 3-17. [verified 6 Jun 2010] http: / / www.alara.net.au / files / ALAR\%20V10\%20No1.pdf

Murcia, K. (2008a). Teaching for scientific literacy with an interactive whiteboard. Teaching Science, 54(4), 17-21.

Murcia, K. (2008b). Teaching science creatively: Engaging primary teacher education students with interactive whiteboard technology. The International Journal of Interdisciplinary Social Sciences, 3(3), 45-52.

$\mathrm{Ng}$, W. (2008). Self-directed learning with web-based sites: How well do students' perceptions and thinking match with their teachers? Teaching Science, 54(2) 24-30.

QSR International (2008). NVivo qualitative data analysis software. QSR International Pty Ltd. http:/ / www.qsrinternational.com/products_nvivo.aspx

Rudd, T. (2007). Interactive whiteboards in the classroom. Futurelab. [viewed 20 Mar 2009, werified 6 Jun 2010] from http:/ / www.futurelab.org.uk/ events/listing/whiteboards/report

Warwick, P. \& Kershner, R. (2008). Primary teachers' understanding of the interactive whiteboard as a tool for children's collaborative learning and knowledge building. Learning, Media and Technology, 33(4), 269-287.

Weinstein, K. (1995). Action learning. London: Harper Collins.

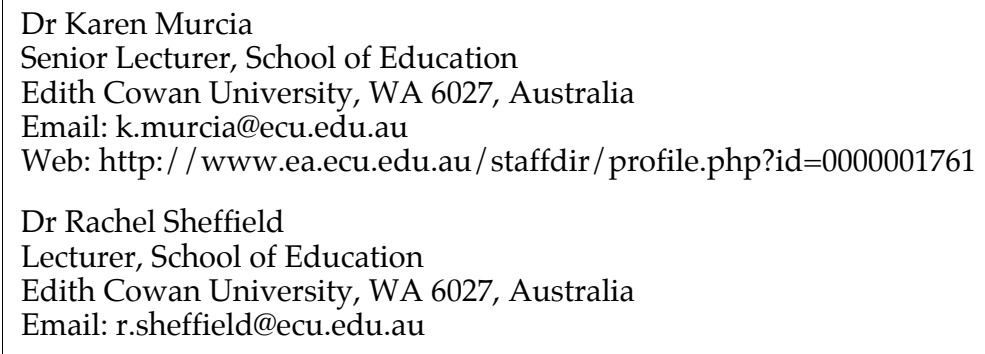

